\title{
Predicting bovine milk protein composition based on Fourier transform infrared spectra
}

\author{
M. J. M. Rutten, ${ }^{* 1}$ H. Bovenhuis, ${ }^{\star}$ J. M. L. Heck, $†$ and J. A. M. van Arendonk ${ }^{\star}$ \\ ${ }^{*}$ Animal Breeding and Genomics Centre, Wageningen University, PO Box 338, $6700 \mathrm{AH}$, Wageningen, the Netherlands \\ †Friesland Campina Research, PO Box 87, 7400 AB, Deventer, the Netherlands
}

\begin{abstract}
Phenotypic information on individual protein composition of cows is important for many aspects of dairy processing with cheese production as the center of gravity. However, measuring individual protein composition is expensive and time consuming. In this study, we investigated whether protein composition can be predicted based on inexpensive and routinely measured milk Fourier transform infrared (FTIR) spectra. Based on 900 calibration and 900 validation samples that had both capillary zone electrophoresis (CZE)-determined protein composition and FTIR spectra available, low to moderate validation $\mathrm{R}^{2}$ were reached (from 0.18 for

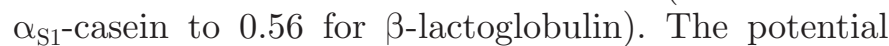
usefulness of this model on the phenotypic level was investigated by means of achieved selection differentials for $25 \%$ of the best animals. For $\alpha$-lactalbumin $\left(\mathrm{R}^{2}=\right.$ 0.20 ), the selection differential amounted to $0.18 \mathrm{~g} / 100$ $\mathrm{g}$ and for casein index $\left(\mathrm{R}^{2}=0.50\right)$ to $1.24 \mathrm{~g} / 100 \mathrm{~g}$. We concluded that predictions of protein composition were not accurate enough to enable selection of individual animals. However, for specific purposes when, for example, groups of animals that meet a certain threshold are to be selected, the presented model could be useful in practice on the phenotypic level. The potential usefulness of this model on the genetic level was investigated by means of genetic correlations between CZE-determined and FTIR-predicted protein composition traits. The genetic correlations ranged from 0.62 ( $\beta$-casein) to 0.97 (whey). Thus, predictions of protein composition, when used as input to estimate breeding values, provide an excellent means for genetic improvement of protein composition. In addition, estimated repeatabilities based on 3 repeated observations of predicted protein composition showed that a considerable amount of prediction error can be removed using repeated observations.
\end{abstract}

Received May 9, 2011.

Accepted July 22, 2011.

${ }^{1}$ Corresponding author: marc.rutten@wur.nl
Key words: milk, protein composition, mid-infrared spectroscopy

\section{INTRODUCTION}

Most dairy breeding organizations worldwide have focused for decades on increasing protein production, mainly because of its importance for cheese production. Within the milk protein fraction, 6 proteins, $\alpha_{\mathrm{S}^{-}}$ casein, $\alpha_{S_{2}}$-casein, $\beta$-casein, $\kappa$-casein, $\alpha$-lactalbumin, and $\beta$-lactoglobulin, can be distinguished that account for approximately $86 \%$ of the total milk protein content (Heck et al., 2008). The remaining approximately $14 \%$ protein consists of at least another 300 different proteins with partly known and partly unknown functions (Hettinga et al., 2011). Not all milk proteins will coagulate during traditional cheese making process (i.e., adding rennet to acidified milk). This is true for the caseins and possibly several other milk proteins, but not true for $\alpha$-lactalbumin and $\beta$-lactoglobulin. Several authors have investigated protein composition in relation to cheese-making properties of milk and have shown significant associations of absolute concentrations of $\kappa$-casein as well as $\kappa$-casein as a fraction of the total casein with rennet clotting time, curd firmness, and cheese production efficiency (Van den Berg et al., 1992; Wedholm et al., 2006; Bonfatti et al., 2010; Penasa et al., 2010). In addition to its relevance for cheese production, protein composition might be of relevance for other aspects of dairy products and dairy processing; for example, production of infant nutrition. Obviously, the availability of information on protein composition of individual animals would enable selection for protein composition. This, in turn, could increase the efficiency of many aspects of dairy processing.

Current methodologies enabling accurate determination of protein composition, such as capillary zone electrophoresis (CZE) and HPLC, are time consuming and expensive and therefore less suitable for large-scale application. Fourier transform infrared spectroscopy (FTIR) could provide an inexpensive alternative to measure protein composition on a routine basis if the accuracy of prediction is at an acceptable level. The use 
of FTIR for the prediction of the total casein content of milk has been reviewed by Broutin (2006) and high accuracy of predictions $\left(\mathrm{R}^{2}>0.9\right)$ can be achieved. The use of FTIR for the prediction of individual caseins and whey proteins in milk is, to our knowledge, limited to the study of De Marchi et al. (2009). However, in that study, proteins were expressed on a milk basis ( $\mathrm{g} /$ $\mathrm{dL}$ ), whereas quantification of protein composition on a protein basis $(\mathrm{g} / 100 \mathrm{~g})$ is required for changing protein composition. To our knowledge, no results with respect to FTIR prediction of protein composition expressed on a protein basis have been published. The aim of this study was to investigate the accuracy of predicting protein composition based on FTIR spectra. In addition, we investigated whether FTIR-predicted protein composition could be used for estimation of genetic parameters and thus for selection.

\section{MATERIALS AND METHODS}

\section{Data}

In total, 5,545 milk samples from 1,917 individual heifers were available for analysis. Milk samples (0.5 L each) were collected during a morning milking. All heifers were in their first lactation and calving dates were between June and December 2004. Milk samples were collected during 3 periods in 2005. The first period ranged from February to March 2005 (winter), the second period ranged from March to May 2005 (spring), and the third period ranged from May to June 2005 (summer). Characteristic differences between winter and summer were that heifers were housed indoors and fed silage in winter, whereas heifers were mostly on pasture in summer. In spring, both indoor housing and grazing were used. In this study, 395 farms spread across the Netherlands were involved and approximately 5 heifers per farm were sampled, all with at least $87.5 \%$ Holstein-Friesian genes. Of those heifers, 888 were sired by 5 proven bulls (each sire having between 102 and 206 daughters in the data set), 840 heifers were sired by 50 young bulls (each sire having between 10 and 24 daughters in the data set), and another 189 heifers were sired by 46 other proven bulls (each sire having between 1 and 32 daughters in the data set). The total pedigree consisted of 26,300 animals.

\section{CZE Analysis}

Milk samples were preserved by adding $0.03 \%$ (wt/ wt) sodium azide, transported refrigerated, and stored at $-40^{\circ} \mathrm{C}$ within $1 \mathrm{~d}$. Subsequently, only the 1,917 winter samples were analyzed using CZE as described by Heck et al. (2008). The CZE-determined protein composition was considered the gold standard in this study. The following protein fractions were identified and quantified: $\alpha_{\mathrm{S}^{-}} \mathrm{CN}, \alpha_{\mathrm{S} 2}-\mathrm{CN}, \beta-\mathrm{CN}, \kappa-\mathrm{CN}$ (i.e., the nonglycosylated, monophosphorylated part, $\kappa-\mathrm{CN}-$ $1 \mathrm{P}), \alpha-\mathrm{LA}$, and $\beta$-LG. In addition, 3 derived traits were calculated: total casein (TCN), the sum of $\alpha_{\mathrm{S1}^{-}}$ $\mathrm{CN}, \alpha_{\mathrm{S}_{2}} \mathrm{CN}, \beta-\mathrm{CN}$, and $\kappa-\mathrm{CN}$; total whey $(\mathbf{T W})$, the sum of $\alpha-\mathrm{LA}$ and $\beta$-LG; and casein index $(\mathbf{C N i})$, the ratio of TCN to the sum of TCN and TW. The CZE data used in this study have been used previously to estimate genetic parameters (Schopen et al., 2009) and to study effects of milk protein variants (Heck et al., 2008).

\section{FTIR Data and Modeling}

The FTIR absorption spectra for all 5,545 milk samples were recorded on $10-\mathrm{mL}$ milk subsamples using MilkoScan FT 6000 equipment (Foss, Hillerød, Denmark) at the certified laboratory of the Milk Control Station (Zutphen, the Netherlands). The spectra consisted of 1,060 infrared frequencies (wavenumbers) ranging from 925 to $5,008 \mathrm{~cm}^{-1}$. Eventually, after combining all data, 1,800 samples were available that were analyzed using both CZE and FTIR. To model relationships between and among milk protein fractions quantified using CZE (dependent) and FTIR (independent variables), partial least squares regression implemented in the $\mathrm{R}$ ( $\mathrm{R}$ Development Core Team, 2008) package PLS (Mevik and Wehrens, 2007) was used. The 1,800 samples were randomly split into 2 equal-sized data sets: a data set for calibration (i.e., establishing the prediction equation) and a data set for model validation. The variable selection strategy of Höskuldsson (2001) was applied to omit irrelevant independent variables. For this purpose, independent variables (the wavenumbers) were ordered according to their average correlation to the dependent variables (CZE protein fractions) expressed on milk basis (g/dL). Subsequently, the 200 highest correlated wavenumbers were selected for modeling. Raw spectra were used for modeling without any mathematical treatment. The number of latent variables (LV) was empirically determined by means of validation in the test data set. Coefficients of determination $\left(\mathrm{R}^{2}\right)$ for the protein fractions were calculated as squared correlations between the CZE-determined protein fractions and FTIR-predicted protein fractions in the validation data set. In addition, the root mean square error of prediction (RMSEP) and the ratio of prediction to error standard deviation (RPD; see Soyeurt et al., 2006) were calculated. Note that all protein fractions were modeled simultaneously (i.e., in a multivariate setting). 


\section{Genetic Modeling}

The FTIR-predicted protein composition was analyzed using 2 genetic models. The first (multivariate genetic) model was used to establish the genetic correlation between milk protein composition based on CZE and FTIR in analogy to Rutten et al. (2010). In the current context, it is important to know to what extent the ranking of animals on EBV for FTIR-predicted traits differs from the ranking of animals on EBV for CZE-determined traits. The latter is directly reflected by the genetic correlation. In this analysis, observations of 1,800 heifers having both CZE-determined and FTIR-predicted protein compositions were analyzed using the following model (Stoop et al., 2008):

$$
\begin{aligned}
& y_{i j k l m n}=\mu+\beta_{1} \times D I M_{i}+\beta_{2} \times e^{-0.05 \times D I M_{i}}+\beta_{3} \times a f c_{j} \\
& +\beta_{4} \times a f c_{j}^{2}+\text { season }_{k}+\text { sirecode }_{l}+f_{m}+a_{n}+e_{i j k l m n},
\end{aligned}
$$

where $y_{i j k l m n}$ is an observation of an FTIR-predicted or CZE-determined protein composition on animal $n$ of farm $m$, with sirecode $l$, age at first calving $j$ observed in season $k$, and DIM $i ; \mu$ is the general mean; $\beta_{1}, \beta_{2}, \beta_{3}$, and $\beta_{4}$ are regression coefficients; $D I M_{i}$ is a covariate for the number of days in milk, modeled with a Wilmink curve (Wilmink, 1987); $a f c_{j}$ is a covariate for the effect of age at first calving; season $n_{k}$ is a fixed effect with 3 classes for season of calving, summer (June to August 2004), fall (September to November 2004), and winter (December 2004 to February 2005); sirecode $e_{l}$ is a fixed effect accounting for possible differences in genetic level between the groups of proven bull daughters and young bull daughters (3 classes: proven bulls, test bulls, and other bulls who did not qualify for one of the latter groups); $f_{m}$ is a random effect of farm $m ; a_{n}$ is a random additive genetic effect for animal $n$; and $e_{i j k l m n}$ is a random residual effect. In matrix notation, the model can be written as

$$
\mathbf{y}=\mathbf{X b}+\mathbf{W f}+\mathbf{Z a}+\mathbf{e}
$$

where $\mathbf{y}$ is a vector of observations on a specific protein both predicted by FTIR and determined by CZE; X is a design matrix for the estimation of $\mathbf{b}$, a vector of fixed effects and regression coefficients; $\mathbf{f}$ is a vector of farm effects; $\mathbf{a}$ is a vector of additive genetic animal effects; $\mathbf{e}$ is a vector of residual effects; and $\mathbf{W}$ and $\mathbf{Z}$ are incidence matrices. In the bivariate analysis, the following assumptions were adopted:

$$
\begin{gathered}
E[\mathbf{y}]=\mathbf{X b}, \\
E[\mathbf{f}]=E[\mathbf{a}]=E[\mathbf{e}]=0, \text { and }
\end{gathered}
$$

$$
V\left[\begin{array}{l}
\mathbf{f} \\
\mathbf{a} \\
\mathbf{e}
\end{array}\right]=\left[\begin{array}{ccc}
\mathbf{I} \otimes \mathbf{F} & 0 & 0 \\
0 & \mathbf{A} \otimes \mathbf{G} & 0 \\
0 & 0 & \mathbf{I} \otimes \mathbf{R}
\end{array}\right],
$$

where $\mathbf{F}$ is a $2 \times 2$ variance-covariance matrix of farm effects for FTIR and CZE protein composition traits; $\mathbf{G}$ is a $2 \times 2$ variance-covariance matrix of additive genetic animal effects for FTIR and CZE protein composition traits; $\mathbf{R}$ is a $2 \times 2$ variance-covariance matrix of residual effects for FTIR and CZE protein composition traits; A is the numerator relationship matrix (Henderson, 1975); I is an identity matrix; and $\otimes$ denotes the Kronecker product operator. Parameters were estimated by REML implemented in ASReml release 2.0 (Gilmour et al., 2006).

The second (univariate repeatability) model was used to analyze 5,545 observations of 1,917 individual heifers. The repeatability indicates to what extent the prediction error of FTIR-predicted traits could be reduced by the collection of repeated observations on the same animal. To this end, FTIR prediction equations based on the winter milk sample were used to predict protein composition for the winter, spring, and summer milk samples. These data were analyzed using a model similar to model 1 , but including a permanent environmental effect $p e_{n}$ for animal $n$ :

$y_{i j k l m n}=\mu+\beta_{1} \times D_{I M_{i}}+\beta_{2} \times e^{-0.05 \times D I M_{i}}+\beta_{3} \times a f c_{j}$
$+\beta_{4} \times a f c_{j}^{2}+$ season $_{k}+$ sirecode $_{l}+f_{m}+a_{n}+p e_{n}+e_{i j k l m n}$.

Intraherd heritabilities (Heringstad et al., 2006) were calculated as

$$
h^{2}=\frac{\sigma_{a}^{2}}{\sigma_{a}^{2}+\sigma_{p e}^{2}+\sigma_{e}^{2}},
$$

where $\sigma_{a}^{2}, \sigma_{p e}^{2}$, and $\sigma_{e}^{2}$ are variances of additive genetic, permanent environmental, and error effects, respectively. Furthermore, farm variance $\left(\sigma_{f}^{2}\right)$ was ignored. Repeatabilities $(r p t)$ were calculated as

$$
r p t=\frac{\sigma_{a}^{2}+\sigma_{p e}^{2}}{\sigma_{a}^{2}+\sigma_{p e}^{2}+\sigma_{e}^{2}} .
$$

\section{Resampling Scheme}

Rutten et al. (2010) showed that resampling of calibration samples for FTIR modeling provides information on the variation in validation $\mathrm{R}^{2}$ as well as genetic 
correlations between the FTIR- and CZE-determined protein composition traits. To quantify this variation, the calibration-validation procedure, as well as all genetic analyses as described above, was repeated 20 times. The resampling scheme consists of the following steps: (1) 900 samples were randomly selected for setting up calibration equations; (2) the remaining 900 samples were then used to calculate validation $\mathrm{R}^{2} ;(3)$ FTIR-predicted protein composition was calculated for all 5,545 samples; (4) genetic correlations were estimated using 1,800 samples with protein composition based on both CZE and FTIR; and (5) heritabilities and repeatabilities were estimated using 5,545 samples with FTIR-predicted protein composition. Variation due to resampling was quantified by taking standard deviations of $\mathrm{R}^{2}$, genetic correlations, heritabilities, and repeatabilities and is referred to here as approximate standard error.

\section{RESULTS AND DISCUSSION}

\section{FTIR Modeling of Protein Fractions}

The results from FTIR modeling of protein composition expressed on a protein basis are presented in Table 1. Average (over 20 random replicates) validation $R^{2}$ ranged from $0.18 \pm 0.06\left(\alpha_{S_{1}}-\mathrm{CN}\right)$ to $0.56 \pm 0.04(\beta-$ $\mathrm{LG}$ ). In terms of $\mathrm{R}^{2}, 2$ groups could be distinguished: TCN, $\alpha_{\mathrm{S}^{-}} \mathrm{CN}, \alpha_{\mathrm{S}^{2}} \mathrm{CN}, \beta-\mathrm{CN}, \kappa-\mathrm{CN}$, and $\alpha-\mathrm{LA}$ showing low validation $\mathrm{R}^{2}(0.19-0.28)$ and $\mathrm{TW}, \beta-\mathrm{LG}$, and $\mathrm{CNi}$ showing moderate validation $\mathrm{R}^{2}(0.50-0.56)$. Both TW and $\mathrm{CNi}$ were highly correlated to $\beta$-LG partly because of the definition of the traits. $\beta$-Lactoglobulin is the only protein fraction that could be predicted reasonably well using FTIR spectroscopy and expressed on a protein basis. Validation $\mathrm{R}^{2}$ for TCN, $\alpha_{\mathrm{S}^{-}} \mathrm{CN}, \alpha_{\mathrm{S} 2}-\mathrm{CN}$, $\beta-\mathrm{CN}$, and $\kappa-\mathrm{CN}$ were all low. The difficulty in predicting TCN and discriminating among different caseins using FTIR might be explained by the fact that in raw milk, $\alpha_{\mathrm{S}^{-}} \mathrm{CN}, \alpha_{\mathrm{S}_{2}} \mathrm{CN}$, and $\beta$-CN occur in micelles, with $\kappa$-CN forming the outer layer of the micelle. Although both $\alpha$-LA and $\beta$-LG are free-floating proteins, only $\beta$-LG showed a moderate validation $R^{2}$. This might be due in part to the lower concentration of $\alpha$-LA compared with $\beta$-LG. Both Soyeurt et al. (2006) and Rutten et al. (2009) have shown that the concentration of, for example, fatty acids is strongly related to prediction $\mathrm{R}^{2}$. In addition to $\mathrm{R}^{2}$, the RMSEP and RPD are presented in Table 1 . When RPD $>1$, the amount of variation explained by the model is larger than the amount of variation that remains unexplained. In this case, RPD of CNi was equal to 1, and RPD of only TW and $\beta$-LG were $>1$ (Table 1 ).

In Figure 1, wavenumbers selected for modeling of milk protein composition are presented. Most wavenumbers were selected from the area around 2,000 $\mathrm{cm}^{-1}$. Wavenumbers from areas that were previously designated as water absorption areas (see Rutten et al., 2011) were not selected. These wavenumbers apparently do not contain information that is highly correlated to the protein composition traits included in the model. Wavenumbers that are known to contain information on milk protein (i.e., several peaks within the area from approximately $1,200 \mathrm{~cm}^{-1}$ to $1,700 \mathrm{~cm}^{-1}$ and from 2,500 $\mathrm{cm}^{-1}$ to $3,000 \mathrm{~cm}^{-1}$; Broutin, 2006) were included in the model (Figure 1). Next to these

Table 1. Mean and standard deviation (SD) of capillary zone electrophoresis (CZE)-determined protein fractions and validation $\mathrm{R}^{2}$, root mean square error of prediction (RMSEP), and the ratio of prediction to error standard deviation (RPD) of Fourier transform infrared (FTIR)-predicted protein fractions expressed on a protein basis $(\mathrm{g} / 100 \mathrm{~g})^{1}$

\begin{tabular}{|c|c|c|c|c|c|}
\hline Trait & $\begin{array}{c}\text { Mean } \\
(\mathrm{n}=1,917)\end{array}$ & $\begin{array}{c}\text { SD } \\
(\mathrm{n}=1,917)\end{array}$ & $\begin{array}{c}\mathrm{R}^{2} \\
(\mathrm{n}=900)\end{array}$ & $\begin{array}{l}\text { RMSEP } \\
(\mathrm{n}=900)\end{array}$ & $\begin{array}{c}\text { RPD } \\
(\mathrm{n}=900)\end{array}$ \\
\hline Protein $\%^{2}$ & 3.51 & 0.30 & $\mathrm{NA}^{3}$ & NA & NA \\
\hline Total casein (TCN) & 75.19 & 1.73 & $0.25 \pm 0.04$ & 1.50 & 0.58 \\
\hline$\alpha_{S 1}-\mathrm{CN}$ & 33.65 & 1.68 & $0.18 \pm 0.06$ & 1.52 & 0.47 \\
\hline$\alpha_{\mathrm{S} 2}-\mathrm{CN}$ & 10.37 & 1.40 & $0.26 \pm 0.06$ & 1.20 & 0.59 \\
\hline$\beta-\mathrm{CN}$ & 27.14 & 1.58 & $0.19 \pm 0.03$ & 1.42 & 0.48 \\
\hline$\kappa-\mathrm{CN}^{4}$ & 4.02 & 0.58 & $0.28 \pm 0.06$ & 0.49 & 0.62 \\
\hline Total whey (TW) & 10.78 & 1.22 & $0.53 \pm 0.04$ & 0.84 & 1.06 \\
\hline$\alpha-L A$ & 2.44 & 0.32 & $0.20 \pm 0.04$ & 0.29 & 0.50 \\
\hline$\beta-\mathrm{LG}$ & 8.34 & 1.19 & $0.56 \pm 0.04$ & 0.79 & 1.13 \\
\hline $\mathrm{CNi}^{5}$ & 87.46 & 1.38 & $0.50 \pm 0.04$ & 0.98 & 1.00 \\
\hline
\end{tabular}

${ }^{1}$ Approximate sampling errors were obtained by taking standard deviations of 20-fold resampled observations. ${ }^{2}$ Determined by FTIR spectroscopy.

${ }^{3} \mathrm{NA}=$ not available.

${ }^{4} \kappa$-Casein-1P, the nonglycosylated, monophosphorylated part, which is approximately $50 \%$ of the total available $\kappa-\mathrm{CN}$.

${ }^{5}$ Casein index, defined as follows: $\mathrm{CNi}=\mathrm{TCN} /(\mathrm{TCN}+\mathrm{TW})$, where TCN $=$ total casein (the sum of $\alpha_{\mathrm{S1}^{-}} \mathrm{CN}$, $\alpha_{\mathrm{S} 2}{ }^{-} \mathrm{CN}, \beta-\mathrm{CN}$, and $\kappa-\mathrm{CN}$ ) and TW = total whey (the sum of $\alpha-\mathrm{LA}$ and $\beta-\mathrm{LG}$ ). 


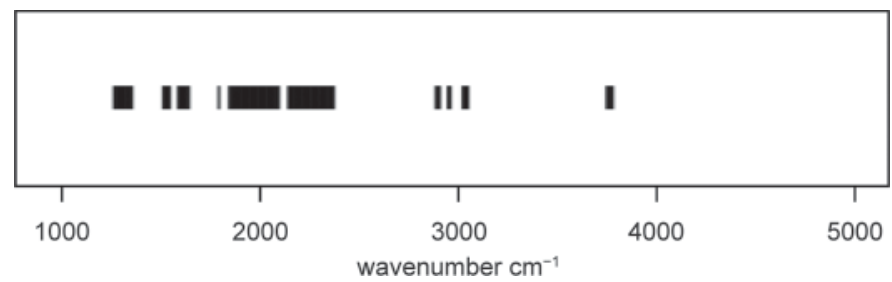

Figure 1. Wavenumbers selected for modeling of milk protein composition.

wavenumbers, several wavenumbers around $2,000 \mathrm{~cm}^{-1}$ were included. Note that due to the different loadings (not shown) attributed to different wavenumbers, some wavenumbers were weighted more heavily than others and thereby had more influence in the final model.

For the FTIR protein composition model, $60 \mathrm{LV}$ were used. The choice of the number of LV is subjective and attempts to maximize validation $\mathrm{R}^{2}$ for all milk proteins and obtain the most parsimonious model. In a multivariate model, this is not an easy task, as illustrated with Figure 2, where the relationship of the number of $L V$ and validation $R^{2}$ is plotted. Figure 2 shows that at least $20 \mathrm{LV}$ are required to reach plateaus of validation $\mathrm{R}^{2}$ for all protein fractions. The optimum number of $\mathrm{LV}$ is around 70 . When the number of $\mathrm{LV}$ exceeds 70 , validation $R^{2}$ of several protein fractions decrease rapidly due to over-fitting of the model. Note that when interest is in the prediction of, for example, $\alpha_{\mathrm{S1}}$-CN only, then $20 \mathrm{LV}$ would suffice. When interest is in the prediction of, for example, $\alpha_{\mathrm{S}^{-}} \mathrm{CN}$, then $60 \mathrm{LV}$ would be required.

De Marchi et al. (2009) investigated the prediction of protein composition on a milk basis $(\mathrm{g} / \mathrm{dL})$ based on FTIR spectra of skim milk. In addition, several studies have investigated the possibility of predicting casein content on a milk basis based on FTIR spectra (Hewavitharana and van Brakel, 1997; Luginbühl, 2002; Sørensen et al., 2003; Broutin, 2006) and the consensus is that high $\mathrm{R}^{2}(>0.9)$ can be obtained. However, to our knowledge, prediction of protein composition expressed on a protein basis $(\mathrm{g} / 100 \mathrm{~g})$ based on FTIR spectra has not been investigated previously, although this information is essential when interest is in changing protein composition, for example. In the specific case of casein, it is not possible to convert FTIR-predicted casein expressed on a milk basis to a protein basis by dividing by the protein content of milk because this strategy would yield an inaccurate model due to the high collinearity of protein and casein content of milk. Generally, it is advisable to express protein composition traits on a protein basis first and then calibrate an FTIR prediction model.

\section{Use of FTIR-Predicted Protein Composition on the Phenotypic Level}

Predictive ability of milk protein composition based on FTIR spectra is low to moderate; however, its potential use in practice might depend strongly upon the application. To this end, some potential applications are discussed. Table 1 shows that $\beta$-LG was the only protein fraction that can be modeled based on milk FTIR spectra with moderate validation $R^{2}$. Both TW and $\mathrm{CNi}$ also showed moderate validation $\mathrm{R}^{2}$, probably because both are closely related to $\beta$-LG. The question arises whether validation $R^{2}$ of these magnitudes allow application of FTIR-based prediction of protein composition in practice. Two potential applications at the phenotypic level are discussed. First, a payment system could be introduced based on FTIR-based prediction of casein content aimed at stimulating increased efficiency for cheese production. To comply with guidelines from the International Dairy Federation with regard to the determination of milk protein using infrared instruments (i.e., IDF standard 141C; IDF, 2000), the standard deviation of the differences between reference and measured results of herd milk samples may not exceed $0.07 \%$, which translates roughly to an $\mathrm{R}^{2}$ of 0.95 . In practice, this value is easily met for milk protein content due to the use of highly accurate commercially available equipment $\left(\mathrm{R}^{2}>0.99\right.$; H. van den Bijgaart, QLIP, Zutphen, The Netherlands, personal communication). The current study indicates that payment based on FTIR-predicted protein composition is therefore not a feasible option.

Another potential application of FTIR-predicted protein composition is to create separate milk streams. To this end, 2 protein composition traits with low and moderate validation $\mathrm{R}^{2}$ are discussed: $\alpha-\mathrm{LA}\left(\mathrm{R}^{2}=0.20\right)$ and $\mathrm{CNi}\left(\mathrm{R}^{2}=0.50\right)$. It is assumed that FTIR information of all cows participating in milk control is available. This information could be used to predict protein composition and subsequently identify cows that have desired values of a certain protein fraction. The milk of these cows could be collected separately. In addition, in the future, it might be possible to record an FTIR milk spectrum during milking, simultaneously predict protein composition, and then decide whether it satisfies a decision rule with respect to the level of a certain protein fraction. Several problems or limitations might inhibit application of these strategies. However, these are not addressed in this paper and these examples are merely for illustrational purposes.

The phenotypic selection differential of a groups of animals can be determined as follows: $\mathrm{S}=i \cdot r \cdot \sigma_{p}$, where $i$ is the selection intensity, $r$ is the correlation between 


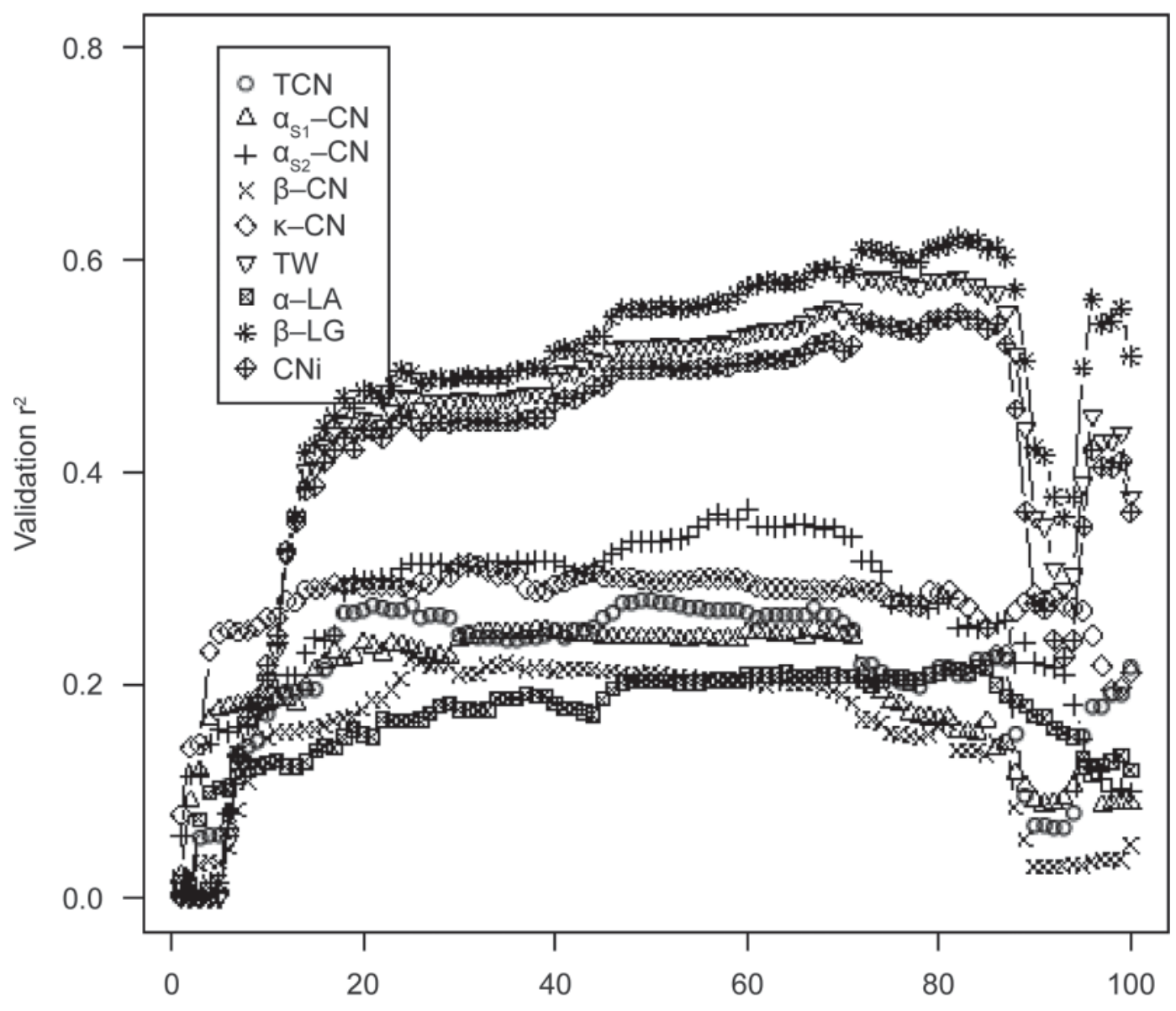

Number of latent variables

Figure 2. The relationship of the number of latent variables used for the multivariate Fourier transform infrared spectroscopy (FTIR) protein composition prediction model and validation $\mathrm{R}^{2}$ of individual protein fractions. Casein index, defined as follows: $\mathrm{CNi}=\mathrm{TCN} /(\mathrm{TCN}+\mathrm{TW})$, where TCN = total casein (the sum of $\alpha_{\mathrm{S} 1}-\mathrm{CN}, \alpha_{\mathrm{S} 2}-\mathrm{CN}, \beta-\mathrm{CN}$, and $\kappa-\mathrm{CN}$ ) and TW = total whey (the sum of $\alpha-\mathrm{LA}$ and $\beta-\mathrm{LG}$ ).

the FTIR-predicted trait and the CZE-determined trait, and $\sigma_{p}$ is the phenotypic standard deviation of CZE-determined trait (assuming that the standard deviation within farms is equal to those reported in Table 1). Suppose the $25 \%$ best animals are selected based on FTIR-predicted $\alpha-\mathrm{LA}$ and $\mathrm{CNi}$. In the case of $\alpha$-LA, this would result in a selection differential of $1.271 \cdot \sqrt{ } 0.20 \cdot 0.32=0.18 \mathrm{~g} / 100 \mathrm{~g}$ over the farm level. Schopen et al. (2009) have shown that considerable herd effects can be identified in protein composition traits. Therefore, when the better herds are selected to implement such a differentiation scenario, substantial contrasts in protein composition traits can be achieved over regional or national levels. For $\mathrm{CNi}\left(\mathrm{R}^{2}\right.$ $=0.50)$, a $25 \%$ selection would result in a contrast of $1.271 \cdot \sqrt{0.50 \cdot 1.38}=1.24 \mathrm{~g} / 100 \mathrm{~g}$.

\section{Use of FTIR-Predicted Protein Composition on the Genetic Level}

Genetic correlations between CZE-determined and FTIR-predicted protein composition traits $(\mathrm{n}=1,800)$ and heritabilities and repeatabilities of FTIR predicted protein composition traits $(\mathrm{n}=5,545)$ are presented in Table 2. Genetic correlations varied from $0.62(\beta-\mathrm{CN})$ to 0.97 (TW). Rutten et al. (2010) showed that the genetic correlation is strongly related to the relative efficiency of FTIR-predicted traits when they are used as selection criteria replacing CZE-determined traits in breeding programs where progeny testing is practiced. For the group of protein composition traits with low $\mathrm{R}^{2}$ (i.e., TCN, $\alpha_{\mathrm{S}^{-}}-\mathrm{CN}, \alpha_{\mathrm{S} 2}-\mathrm{CN}, \beta-\mathrm{CN}, \kappa-\mathrm{CN}$, and $\alpha-\mathrm{LA}$ ), the presented FTIR-predicted protein composition 
Table 2. Genetic correlations $\left(\mathrm{r}_{\mathrm{g}}\right)$ between capillary zone electrophoresis (CZE)-determined and Fourier transform infrared (FTIR)-predicted protein fractions and intra-herd heritabilities $\left(\mathrm{h}^{2}{ }_{\text {FTIR }}\right)$ and repeatabilities $\left(\mathrm{rpt}_{\mathrm{FTIR}}\right)$ of FTIR-predicted protein fractions and their approximate sampling errors ${ }^{1}$

\begin{tabular}{lccc}
\hline Trait & $\begin{array}{c}\mathrm{r}_{\mathrm{g}} \\
\mathrm{n}=1,800)\end{array}$ & $\begin{array}{c}\mathrm{h}_{\mathrm{FTTR}}^{2} \\
(\mathrm{n}=5,545)\end{array}$ & $\begin{array}{c}\mathrm{rpt}_{\mathrm{FTIR}} \\
(\mathrm{n}=5,545)\end{array}$ \\
\hline Total casein (TCN) & $0.74 \pm 0.04$ & $0.34 \pm 0.03$ & $0.45 \pm 0.03$ \\
$\alpha_{\mathrm{S} 1^{-}} \mathrm{CN}$ & $0.66 \pm 0.09$ & $0.32 \pm 0.08$ & $0.33 \pm 0.07$ \\
$\alpha_{\mathrm{S} 2}-\mathrm{CN}$ & $0.80 \pm 0.04$ & $0.35 \pm 0.08$ & $0.35 \pm 0.08$ \\
$\beta-\mathrm{CN}$ & $0.62 \pm 0.08$ & $0.23 \pm 0.03$ & $0.39 \pm 0.05$ \\
$\kappa-\mathrm{CN}$ & $0.78 \pm 0.04$ & $0.44 \pm 0.05$ & $0.47 \pm 0.06$ \\
Total whey (TW) & $0.97 \pm 0.01$ & $0.57 \pm 0.03$ & $0.60 \pm 0.03$ \\
$\alpha-\mathrm{LA}$ & $0.69 \pm 0.05$ & $0.36 \pm 0.05$ & $0.36 \pm 0.05$ \\
$\beta-\mathrm{LG}$ & $0.96 \pm 0.01$ & $0.59 \pm 0.03$ & $0.63 \pm 0.03$ \\
$\mathrm{CNi}^{3}$ & $0.96 \pm 0.01$ & $0.55 \pm 0.03$ & $0.60 \pm 0.03$ \\
\hline
\end{tabular}

${ }^{1}$ Approximate sampling errors were obtained by taking standard deviations of 20-fold resampled observations. ${ }^{2} \kappa$-Casein-1P, the nonglycosylated, monophosphorylated part, which is approximately $50 \%$ of the total available $\kappa-\mathrm{CN}$.

${ }^{3}$ Casein index, defined as follows: $\mathrm{CNi}=\mathrm{TCN} /(\mathrm{TCN}+\mathrm{TW})$, where TCN $=$ total casein (the sum of $\alpha_{\mathrm{S}_{1}-} \mathrm{CN}$, $\alpha_{\mathrm{S}^{-}} \mathrm{CN}, \beta-\mathrm{CN}$, and $\kappa-\mathrm{CN}$ ) and TW = total whey (the sum of $\alpha-\mathrm{LA}$ and $\beta-\mathrm{LG}$ ).

reached genetic correlations of at least $0.62(\beta-\mathrm{CN})$. For the group of protein composition traits with moderate $\mathrm{R}^{2}$ (TW, $\beta$-LG, and CNi), the FTIR-predicted protein composition reached average genetic correlations of 0.96 or higher. The genetic correlations and heritabilities show that the use of FTIR-predicted protein composition as an information source enabling a breeding value estimation procedure and subsequent selection purpose has excellent potential. The use of FTIR-predicted TW or $\mathrm{CNi}$ allows genetic selection to improve efficiency of cheese production. In addition, the genetic correlation between, for example, FTIR-predicted $\mathrm{CNi}$ and protein content $(0.04$; not shown) indicates that selection for improved cheese production efficiency can be achieved independently from protein content of milk.

Intra-herd heritabilities ranged from moderate to high (0.23-0.59; Table 2). In general, traits from the groups with moderate $\mathrm{R}^{2}$ had the highest heritabilities (0.55-0.59). The heritabilities of FTIR-predicted traits were considerably lower $(0.17$; not shown) than the heritabilities of CZE-determined traits presented previously by Schopen et al. (2009). This follows directly from the fact that FTIR-predicted traits are approximations of, in this case, CZE-determined traits. Prediction error of the FTIR model is analogous to measurement error and it is known that when measurement error decreases, heritability increases (e.g., Falconer and Mackay, 1996).

Repeatabilities (Table 2) ranged from $0.33\left(\alpha_{\mathrm{S1}^{-}} \mathrm{CN}\right)$ to 0.63 ( $\beta-\mathrm{LG})$ and show that considerable gains in accuracy of estimated animal effects can be achieved by collection of repeated records on the same animals. Due to the systematic collection of milk FTIR spectra for milk control purposes, a wealth of information could be made available that ultimately enables selection for several protein composition traits independently from milk protein content. When mass selection for CZE-determined casein is considered, the accuracy of selection based on 1 observation of FTIR-predicted TCN gives an accuracy of 0.58 . The accuracy of selection increases to 0.78 after 5 observations have been made and to 0.82 after 10 observations have been made. In the case of $\mathrm{CNi}$, accuracies for the same number of observations are $0.74,0.90$, and 0.93 respectively.

\section{CONCLUSIONS}

Modeling of protein composition based on milk FTIR spectra yielded a moderate validation $\mathrm{R}^{2}$ for $\beta-\mathrm{LG}(0.56)$ but low validation $\mathrm{R}^{2}$ for $\alpha_{\mathrm{S}^{-}} \mathrm{CN}, \alpha_{\mathrm{S} 2}-\mathrm{CN}, \beta-\mathrm{CN}, \kappa-\mathrm{CN}$, and $\alpha$-LA $(0.20-0.28)$. Despite moderate to low validation $\mathrm{R}^{2}$, FTIR-predicted protein composition traits might be useful when groups of animals are selected on the phenotypic level. Genetic correlations between CZE-determined and FTIR-predicted protein composition traits varied between 0.62 and 0.97 and suggest that FTIR-predicted protein composition in a breeding value estimation procedure has excellent potential when changes in protein composition are desired.

\section{ACKNOWLEDGMENTS}

This study was part of the Milk Genomics Initiative and the project "Melk op maat," funded by Wageningen University, the Dutch Dairy Association (NZO, Zoetermeer, the Netherlands), CRV (cooperative cattle improvement organization, Arnhem, the Netherlands), the Dutch Technology Foundation (STW, Utrecht, the Netherlands), the Dutch Ministry of Economic Affairs (The Hague, the Netherlands) and the provinces of Gelderland (Arnhem, the Netherlands) and Overijssel 
(Zwolle, the Netherlands). The authors acknowledge the participating herd owners and the Dutch Milk Control Station (Qlip, Zutphen, the Netherlands).

\section{REFERENCES}

Bonfatti, V., G. Di Martino, A. Cecchinato, L. Degano, and P. Carnier. 2010. Effects of $\beta$-к-casein (CSN2-CSN3) haplotypes, $\beta$-lactoglobulin (BLG) genotypes, and detailed protein composition on coagulation properties of individual milk of Simmental cows. J. Dairy Sci. 93:3809-3817.

Broutin, P. J. 2006. New application of mid-infrared spectrometry for the analysis of milk and milk products: Casein. Bull. Int. Dairy Fed. 406:2-21.

De Marchi, M., V. Bonfatti, A. Cecchinato, G. Di Martino, and P. Carnier. 2009. Prediction of protein composition of individual cow milk using mid-infrared spectroscopy. Ital. J. Anim. Sci. 8:399401.

Falconer, D. S., and T. F. C. Mackay. 1996. Introduction to Quantitative Genetics. 4th ed. Longmans Green, Harlow, UK.

Gilmour, A. R., B. J. Gogel, B. R. Cullis, and R. Thompson. 2006. ASReml user guide release 2.0. VSN International Ltd., Hemel Hempstead, UK.

Heck, J. M. L., C. Olieman, A. Schennink, H. J. F. van Valenberg, M. H. P. W. Visker, R. C. R. Meuldijk, and A. C. M. van Hooijdonk. 2008. Estimation of variation in concentration, phosphorylation and genetic polymorphism of milk proteins using capillary zone electrophoresis. Int. Dairy J. 18:548-555.

Henderson, C. R. 1975. Rapid method for computing the inverse of a relationship matrix. J. Dairy Sci. 58:1727-1730.

Heringstad, B., D. Gianola, Y. M. Chang, J. Odegard, and G. Klemetsdal. 2006. Genetic associations between clinical mastitis and somatic cell score in early first-lactation cows. J. Dairy Sci. $89: 2236-2244$.

Hettinga, K., H. van Valenberg, S. de Vries, S. Boeren, T. van Hooijdonk, J. van Arendonk, and J. Vervoort. 2011. The host defense proteome of human and bovine milk. PLoS ONE 6:e19433.

Hewavitharana, A. K., and B. van Brakel. 1997. Fourier transform infrared spectrometric method for the rapid determination of casein in raw milk. Analyst (Lond.) 122:701-704.

Höskuldsson, A. 2001. Variable and subset selection in PLS regression. Chemom. Intell. Lab. Syst. 55:23-38.

IDF. 2000. IDF standard 141C: Determination of milkfat, protein and lactose content - Guidance on the operation of mid-infrared instruments. International Dairy Federation, Brussels, Belgium.

Luginbühl, W. 2002. Evaluation of designed calibration samples for casein calibration in Fourier transform infrared analysis of milk. Lebenson. Wiss. Technol. 35:554-558.
Mevik, B. H., and R. Wehrens. 2007. The PLS package: Principal component and partial least squares regression in R. J. Stat. Softw. 18:1-24.

Penasa, M., M. Cassandro, D. Pretto, M. De Marchi, A. Comin, S. Chessa, R. Dal Zotto, and G. Bittante. 2010. Short communication: Influence of composite casein genotypes on additive genetic variation of milk production traits and coagulation properties in Holstein-Friesian cows. J. Dairy Sci. 93:3346-3349.

R Development Core Team. 2008. R: A language and environment for statistical computing. R Foundation for Statistical Computing, Vienna, Austria.

Rutten, M. J. M., H. Bovenhuis, J. M. L. Heck, and J. A. M. van Arendonk. 2011. Prediction of $\beta$-lactoglobulin genotypes based on milk Fourier transform infrared spectra. J. Dairy Sci. 94:4183-4188. doi:10.3168/jds.2011-4149.

Rutten, M. J. M., H. Bovenhuis, K. A. Hettinga, H. J. F. van Valenberg, and J. A. M. van Arendonk. 2009. Predicting bovine milk fat composition using infrared spectroscopy based on milk samples collected in winter and summer. J. Dairy Sci. 92:6202-6209.

Rutten, M. J. M., H. Bovenhuis, and J. A. M. van Arendonk. 2010 The effect of the number of observations used for Fourier transform infrared model calibration for bovine milk fat composition on the estimated genetic parameters of the predicted data. J. Dairy Sci. 93:4872-4882.

Schopen, G. C. B., J. M. L. Heck, H. Bovenhuis, M. H. P. W. Visker, H. J. F. van Valenberg, and J. A. M. van Arendonk. 2009. Genetic parameters for major milk proteins in Dutch Holstein-Friesians. J. Dairy Sci. 92:1182-1191.

Sørensen, L. K., M. Lund, and B. Juul. 2003. Accuracy of Fourier transform infrared spectrometry in determination of casein in dairy cows' milk. J. Dairy Res. 70:445-452.

Soyeurt, H., P. Dardenne, F. Dehareng, G. Lognay, D. Veselko, M. Marlier, C. Bertozzi, P. Mayeres, and N. Gengler. 2006. Estimating fatty acid content in cow milk using mid-infrared spectrometry. J. Dairy Sci. 89:3690-3695.

Stoop, W. M., J. A. M. van Arendonk, J. M. L. Heck, H. J. F. van Valenberg, and H. Bovenhuis. 2008. Genetic parameters for major milk fatty acids and milk production traits of Dutch HolsteinFriesians. J. Dairy Sci. 91:385-394.

Van den Berg, G., J. T. M. Escher, P. J. de Koning, and H. Bovenhuis. 1992. Genetic polymorphism of k-casein and $\beta$-lactoglobulin in relation to milk composition and processing properties. Neth. Milk Dairy J. 46:145-168.

Wedholm, A., L. B. Larsen, H. Lindmark-Månsson, A. H. Karlsson, and A. Andrén. 2006. Effect of protein composition on the cheesemaking properties of milk from individual dairy cows. J. Dairy Sci. 89:3296-3305.

Wilmink, J. B. M. 1987. Adjustment of test-day milk, fat and protein yield for age, season and days-in-milk. Livest. Prod. Sci $16: 335-348$. 